\title{
Genetic Determinants of Musculoskeletal Adaptations to Unloading and Reloading
}

\author{
Engin Ozcivici \\ Department of Bioengineering \\ Izmir Institute of Technology \\ Izmir, Turkey \\ enginozcivici@iyte.edu.tr
}

\author{
Stefan Judex \\ Department of Biomedical Engineering \\ Stony Brook University \\ Stony Brook, NY, USA \\ stefan.judex@stonybrook.edu
}

\begin{abstract}
Lack of weight bearing is one of the most critical limitations for long term health of bone tissue in space missions. In this study, we performed a series of Quantitative Trait Locus (QTL) analysis of musculoskeletal traits to define genomic modulators adaptations to mechanical unloading and subsequent reloading using a genetically heterogeneous (F2 BALBxC3H) female mouse population. The identified regions on genome contain genes that regulate musculoskeletal adaptations to weightlessness and further studies may help to categorize individuals that are at risk for greater tissue loss during weightlessness and/or low tissue recovery during reambulation.
\end{abstract}

Keywords—mechanical loading, QTL, bone, muscle, stress

\section{INTRODUCTION}

Mechanical loads are important regulators of molecular events in bone cells that determine bone tissue mass and morphology during development and homeostasis [1-2]. Therefore, lack of load bearing, such as during spaceflight, induce catabolism in bone tissue. Astronauts lose $2 \%$ of their bone mass and $5 \%$ of mechanical strength per month of weightlessness exposure [3-5]. Upon returning to regular weight bearing conditions, recovery rates are significantly slower compared to the rate of loss some morphological traits may never be completely recovered [6].

Though spaceship crew is exposed to net bone loss during spaceflights, the net change is marked by high variability in distribution, indicating an important role of genetic factors in the magnitude of change [7]. To identify the regions on the genome that modulate musculoskeletal response to mechanical unloading and reloading, we designed a linkage study with a genetically heterogeneous mouse population. This population was bred with two progenitor strains (BALB and $\mathrm{C} 3 \mathrm{H}$ ) that show a distinct skeletal response to mechanical unloading.

\section{METHODS}

All procedures were reviewed and approved by the Stony Brook University, The Institutional Animal Care and Use Committee (IACUC). In order to breed the F2 population, we used female BALB (high tissue loss during unloading) and male $\mathrm{C} 3 \mathrm{H}$ (low tissue loss during unloading) mice. Female mice from F2 generation were selected at skeletal maturity (4 months old, $\mathrm{n}=352$ ) and were exposed to 3 weeks of hindlimb unloading. After mechanical unloading, mice were released to 3 weeks of unconstrained reambulation [8]. Parameters pertaining to the musculoskeletal tissue were collected via in vivo $\mu \mathrm{CT}$ scans that were completed at baseline, after mechanical unloading and after reambulation for trabecular bone in proximal femur as well as muscle tissue surrounding diaphyseal femur. DNA required for SNP identification were collected from tail tissue. Trabecular regions in $\mu \mathrm{CT}$ scans $(17.5 \mu \mathrm{m}$ voxel size $)$ were subjected to a semi-automatic image processing algorithm to be separated from surrounding cortical tissue [9]. $\mu \mathrm{CT}$ segments were then translated into a Finite Element Model (FEM) to simulate trabecular bone's mechanical properties under uniform compression along the loading direction [10]. For each musculoskeletal phenotype, separate QTL analysis was solved in silico via R/QTL statistical software. For each phenotype, the LOD score exceeding statistical thresholds were reported.

\section{RESULTS AND DISCUSSION}

During 3 weeks of unloading, mice lost $43 \%$ of their trabecular bone volume fraction $(\mathrm{BV} / \mathrm{TV})$ on average with a wide range (15\%-71\%) as expected from a genetically heterogeneous population. During reambulation, BV/TV increased by $10 \%(-18 \%$ to $56 \%)$. QTL results showed that more than $20 \%$ of statistical variability in mechanical unloading induced loss in BV/TV was explained by six different genomic locations on different chromosomes. In turn, a single significant QTL on chromosome 13 explained $6 \%$ of the unconstrained reambulation induced statistical variability in BV/TV [11]

Similar to morphological traits, during 3 weeks of unloading trabecular bone stiffness was reduced by $42 \% \pm 19 \%$ with a $27 \% \pm 15 \%$ increase in maximum VonMises Stresses. During reambulation stiffness increased $13 \% \pm 31$ and maximum stresses decreased $10 \% \pm 8 \%$. For maximum stress levels, 3 locations on genome accounted for $14 \%$ of variability during unloading and one genomic locus accounted for 5\% of variability during reambulation [12]. For maximum stress, which is an important indicator of bone tissue's risk of failure, identified QTLs contained 70 genes for unloading and 11 genes for reambulation that are important in bone formation as well as bone resorption.

Aside from the genetic analysis, the correlation between mechanical and morphological traits was strong in control mice. However, this correlation progressively decreased during the unloading and the reambulation. Although the increase of trabecular bone tissue was limited during the recovery, as observed from a minor increase in BV/TV, maximum stress values that indicated mechanical risk of skeletal fracture decreased by $56 \%$. During reambulation phase, $66 \%$ of the mice showed positive BV/TV change while a larger group of $89 \%$ of all mice showed decreased maximum stress levels out of the entire F2 population. After reambulation, only $8 \%$ of the population recovered half of the losses in BV/TV while $50 \%$ of the population restored

Funding: NASA NAG 9-1499 (SJ) 
half of the deterioration in maximum stresses. $12 \%$ of the population showed close to complete recovery of maximum stress, while only $5 \%$ of mice showed complete recovery of $\mathrm{BV} / \mathrm{TV}$. Recovery of mechanical properties over bulk bone mass indicates that restoration of mechanical integrity is preferential before the morphology [13]

During the 3 weeks of mechanical unloading muscle area declined on average by $9 \%$, while during reambulation mice recovered most of their losses with a $9 \%$ increase in muscle area. However, the genome analysis identified only a single QTL for the loss in muscle cross section during unloading, but no QTLs for muscle increase during reambulation was found. Both during mechanical unloading and reambulation, correlations between changes in muscle area and changes in bone were very low, indicating that muscle and bone adaptations are differentially regulated [14].

\section{CONCLUSIONS}

The identified QTLs contain genes that regulate musculoskeletal adaptations to weightlessness and further studies may help to identify spaceship crew that are at greater risk for musculoskeletal deteriorations during weightlessness and/or low tissue recovery during reambulation. The structural processes of trabecular bone recovery suggest that bone tissue attempts to restore mechanical properties before restoring the bone mass, indicating a potential route to be manipulated after space missions. Also, mechanical unloading / reambulation associated genes may be targeted in further ground based weightlessness studies [15].

\section{ACKNOWLEDGMENT}

Help from Svetlana Lublinsky, Shiyun Xu for $\mu \mathrm{CT}$ scans and Weidong Zhang, Leah Rae Donahue for QTL analysis is gratefully acknowledged.

\section{REFERENCES}

[1] E. Ozcivici, Y. K. Luu, B. Adler, Y.X. Qin, J. Rubin, S. Judex, C. T. Rubin, "Mechanical signals as anabolic agents in bone," Nat Rev Rheumatol, 6:50-9, 2010.
[2] E. Ozcivici, "Effects of spaceflight on cells of bone marrow origin," Turk J Hematol, 30:1-7, 2013.

[3] L. Vico, P. Collet, A. Guignandon, M. H. Lafage - Proust, T. Thomas, M. Rehaillia, C. Alexandre, "Effects of long - term microgravity exposure on cancellous and cortical weight - bearing bones of cosmonauts," Lancet, 355(9215):1607-11, 2000.

[4] T. Lang, A. LeBlanc, H. Evans, Y. Lu, H. Genant, A. Yu, “Cortical and trabecular bone mineral loss from the spine and hip in long duration spaceflight," J Bone Miner Res, 19(6):1006-12, 2004.

[5] J. H. Keyak, A. K. Koyama, A. LeBlanc, Y. Lu, T.F. Lang, "Reduction in proximal femoral strength due to long-duration spaceflight," Bone, 44:449-53, 2009.

[6] J. D. Sibonga, H. J. Evans, H. G.Sung, E. R. Spector, T. F. Lang, V.S. Oganov, A. V. Bakulin, L. C. Shackelford, A. D. LeBlanc, "Recovery of spaceflight-induced bone loss: bone mineral density after longduration missions as fitted with an exponential function," Bone 41:973-8, 2007.

[7] S. Judex, R. Garman, M. Squire, B. Busa, L. R.Donahue, C. Rubin, "Genetically linked site specificity of disuse osteoporosis," J Bone Miner Res, 19:607-13, 2004.

[8] E. Ozcivici, Y. K. Luu, C. T. Rubin, S. Judex, "Low-level vibrations retain bone marrow's osteogenic potential and augment recovery of trabecular bone during reambulation," PLoS One, 5:e11178, 2010.

[9] S. Lublinsky, E. Ozcivici, S. Judex, "An automated algorithm to detect the trabecular cortical bone interface in micro-computed tomographic images," Calcif Tissue Int, 81:285-93, 2007.

[10] E. Ozcivici, R. Garman, S Judex, "High-frequency oscillatory motions enhance the simulated mechanical properties of non-weight bearing trabecular bone," J Biomech, 40:3404-11, 2007.

[11] S. Judex, W. Zhang, L.R. Donahue, E. Ozcivici, "Genetic loci that control the loss and regain of trabecular bone during unloading and reambulation," J Bone Miner Res, 28:1537-49, 2013.

[12] E. Ozcivici, W. Zhang, L. R. Donahue, S. Judex, "Quantitative trait loci that modulate trabecular bone's risk of failure during unloading and reloading," Bone, 64:25-32, 2014.

[13] E. Ozcivici, S. Judex, "Trabecular bone recovers from mechanical unloading primarily by restoring its mechanical function rather than its morphology," Bone, 67:122-129, 2014.

[14] S. Judex, W. Zhang, L.R. Donahue, E. Ozcivici, "Genetic and tissue level muscle-bone interactions during unloading and reambulation," Musculoskelet Neuronal Interact, 16(3):174-182, 2016.

[15] M. Anil-Inevi et al., "Biofabrication of in situ self assembled 3D cell cultures in a weightlessness environment generated using magnetic levitation," Scientific Reports, vol. 8, no. 1, p. 7239, 2018. 